Sains Malaysiana 49(4)(2020): 929-940

http://dx.doi.org/10.17576/jsm-2020-4904-22

\title{
Hybrid Multistep Block Method for Solving Neutral Delay Differential Equations
} (Kaedah Blok Multi Langkah Hibrid Bagi Menyelesaikan Persamaan Pembezaan Lengah Neutral)

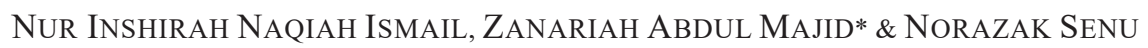

\section{ABSTRACT}

The initial-value problem for first order single linear neutral delay differential equations (NDDEs) of constant and pantograph delay types have been solved by using hybrid multistep block method. The method has been derived by applying Taylor series interpolation polynomial and implementing the predictor-corrector formulas in $P E(C E)^{m}$ mode where $m$ is the number of iterations for the proposed method. Both types of NDDEs will be solved at two-point simultaneously including the off-step point with constant step-size. In order to find the solution for NDDEs, the delay solutions of the unknown function will be interpolated using Lagrange interpolation polynomial and the derivative of the delay solutions will be obtained by applying divided difference formula. The order, consistency and convergence of the proposed method have been discussed in detail in the methods section. The properties of stability region for NDDEs have also been analysed. Numerical results presented have concluded that the proposed method is comparable with the existing method and is assumed to be reliable for solving first order NDDEs with constant and pantograph delay.

Keywords: Constant delay; multistep block method; neutral delay differential equations; off-step point; pantograph delay

\section{ABSTRAK}

Masalah nilai permulaan untuk terbitan pertama tunggal linear Persamaan Pembezaan Lengah Neutral (PPLN) bagi jenis kelengahan malar dan pantograf telah diselesaikan dengan menggunakan kaedah blok multi langkah hibrid. Kaedah ini diperoleh dengan menggunakan polinomial penyuaian siri Taylor dan melaksanakan rumusan peramal pembetul dalam mod PE(CE) ${ }^{m}$ dengan $m$ adalah bilangan pengulangan bagi kaedah yang dicadangkan. Kedua-dua jenis PPLN akan diselesaikan pada dua titik serentak termasuk titik luar langkah dengan saiz langkah yang malar. Bagi mencari penyelesaian untuk PPLN, nilai kelengahan bagi fungsi yang tidak diketahui akan diperoleh melalui penggunaan polinomial penyuaian Lagrange dan pembezaan penyelesaian kelengahan akan diperoleh dengan menggunakan formula perbezaan pembahagian. Penentuan peringkat, tahap konsistensi dan penumpuan bagi kaedah yang dicadangkan telah dibincangkan secara terperinci dalam bahagian metod. Ciri-ciri kawasan kestabilan untuk PPLNjuga telah dianalisis. Keputusan berangka yang dibentangkan telah menyimpulkan bahawa kaedah yang dicadangkan adalah setanding dengan kaedah yang telah sedia ada dan dianggap dapat menyelesaikan peringkat pertama PPLN dengan kelengahan malar dan pantograf.

Kata kunci: Kaedah blok multi langkah; ketundaan malar; ketundaan pantograf; persamaan pembezaan lengah neutral; titik luar langkah

\section{INTRODUCTION}

Recent Recent development of science and technology has discovered a number of analytical and numerical methods. Nowadays, Neutral Delay Differential Equations (NDDEs) commonly arises in numerous occurrences and has represented significant role in dealing with real life phenomena especially on their application in biological and physiological processes. For instance, the delay term can be presented as a transport delay which can be described as a signal to travel to the controlled object as quoted by Kuang (1993). The aim of this research was to relate the application of NDDEs related to cell growth phenomena with delay in its development which are denoted as shown:

$$
\begin{array}{ll}
y^{\prime}(x)=\rho_{0} y(x)+\rho_{1} y\left(x-\tau_{i}\right)+\rho_{2} y^{\prime}\left(x-\sigma_{\mathrm{i}}\right), & x \geq x_{0} \\
y(x)=\phi(x), & x \leq x_{0} \\
y^{\prime}(x)=\phi^{\prime}(x), & x \leq x_{0}
\end{array}
$$

and

$$
\begin{array}{ll}
y^{\prime}(x)=\rho_{0} y(x)+\rho_{1} y(q x)+\rho_{2} y^{\prime}(q x), & x \geq x_{0} \\
y(x)=\phi(x), & x \leq x_{0}
\end{array}
$$


where $\phi(x)$ need to be differentiable once and still continuous along the interval $x \in\left(-\infty, x_{0}\right]$. The idea of (1) and (2) have been obtained from Baker et al. (2008). Equation (1) is NDDEs with constant delay while (2) is NDDEs with proportional delay and also known as pantograph equation where $0<q<1$ and $y(x)=\phi(x)$ is the given initial value. The constants $\tau_{i}$ and $\sigma_{i}$ are the delays while $\left(\mathrm{x}-\tau_{i}\right)$ and $\left(\mathrm{x}-\sigma_{i}\right)$ are the expressions of delay solutions. The value of $\rho$ has its own interpretation, for example, the biological interpretation for $\tau \geq 0$ means the average cell-division time for each human body. Further, $-\rho_{0} \geq 0$ is the cell-death rate, $\rho_{1} \geq 0$ is the commitment to the cell-division process rate and $0 \leq$ $\rho_{2} \leq 2$ indicates the gradual dispersal of synchronization of cell-division where if $\rho_{2}=2$, then it implies a perfect synchronization (Baker et al. 2008). NDDEs have been investigated by many researchers and several analytical and numerical methods have been established in order to find the approximations to the NDDEs problems.

The numerical techniques for NDDEs have been mostly discovered by Jackiewicz. In 1982, Adams type methods had been proposed by Jackiewicz (1982) for the special case of NDDEs. Few years later, a new class of one-step methods for the numerical solution of NDDEs had been considered by Jackiewicz (1984) and the theory of quasilinear multistep methods and predictor-corrector methods for NDDEs had been developed by Jackiewicz (1986). Jackiewicz (1987) had also described the variablestep variable-order algorithm based on predictorcorrector methods for NDDEs. An algorithm based on unequal-interval Adams-Bashforth Adams-Moulton predictor-corrector methods with step-size and order changing strategy had been explained by Jackiewicz and Lo (1991). A variable-step and variable-order algorithm based on the formulation of Adam methods in divided difference form had been demonstrated by Jackiewicz and Lo (2006). Bellen and Guglielmi (2009) had solved state dependent delay type where the discontinuity in the derivative may exist which is called as 'breaking point'. They had produced a method to generalize the solutions beyond the 'breaking point'. Variational iteration method (VIM) had been applied by Chen and Wang (2010) while homotopy perturbation method (HPM) had been illustrated by Biazar and Ghanbari (2012) to solve NDDEs with proportional delay. Later, Lv and Gao (2013) had proposed so-called the reproducing kernel Hilbert space method (RKHSM) where the performance of these three methods had been compared with a particular Runge-Kutta (RK) method and a one-leg -method which had been proposed by Wang and Li (2007) and Wang et al. (2009), respectively. A two-point block method for solving NDDEs of proportional delay type had been derived by Ishak et al. (2013). The implementation was based on variable step-size strategy where the numerical results had demonstrated the accuracy and efficiency of the block method. The stability analysis of the block method had been illustrated by Ishak et al. (2014). Ishak and Ramli (2015) had developed an implicit block method using variable step-size while Seong and Majid (2015) had implemented the use of two-point block method in the form of predictor-corrector Adams-Moulton to solve first order NDDEs of pantograph type. Block methods had also been applied widely in solving Ordinary Differential Equation (ODE) and Volterra Integrodifferential Equation (VIDE) as stated in Ibrahim et al. (2019), Ismail et al. (2018), and Majid and Mohamed (2019). Ismail et al. (2018) had derived a fifth order twopoint block explicit hybrid method where the method was trigonometrically fitted to create a suitable approach in solving highly oscillatory problems of special second order ODE. In 2019, Majid and Mohamed had proposed a fifth order two-point multistep block method in the form of Adams Moulton type to solve the linear and non-linear VIDE while Ibrahim et al. (2019) had formulated the third, fourth and fifth orders of two-point block backward differentiation formulas (BBDF) for the numerical solution of second order ODE. The methods had been implemented in variable order strategy and the numerical results obtained had illustrated the advantage of applying the proposed method. In order to solve delay problems, Ahmad and Fatima (2016) had introduced a Differential Transform method (DTM) to be applied on NDDEs with proportional delay. More recently, a homotopy analysis method (HAM) had been improved by Sakar (2017) where the numerical results had concluded that the method is very simple and effective to be used to solve NDDEs with proportional delays. Liu et al. (2019) had been focusing on the stability analysis of state and time dependent delay types.

As has been known by many researchers, the exact solutions for NDDEs are very difficult and sometimes almost impossible to be obtained. Thus, a numerical method is the best approach to approximate the solutions as accurate as possible. In this research, a twopoint implicit hybrid multistep block method (2PIH) is numerically applied to NDDEs with constant and pantograph delay types. The motivation of proposing $2 \mathrm{PIH}$ is due to the fact that the combination of both hybrid and block methods has reduced the computational cost while the error can still be minimized without relying on a very fine time step. Besides, none of the researchers have solved NDDEs using an off-point with a block method. Most of the previous authors have also focused more on analytical method compared to numerical method. Nevertheless, some researchers have proposed a series of one-step and multistep method for the numerical solutions of NDDEs. The purpose of this research was to extend the work from previous multistep method in becoming a multistep block with the existing of an off-point.

\section{METHODS}

In this section, the development of $2 \mathrm{PIH}$ will be described concisely to show the efficiency of the proposed method in 
solving real life problems. Based on Majid and Suleiman (2011), a two-point block predictor-corrector method has been adapted and modified into two-point off-step block method. In order to get the approximation values of $y_{n+\frac{1}{2}}$ $y_{n+1}$ and $y_{n+2}$, the interval $[a, b]$ will be subdivided into a series of block. Each blocks containing two points including the off-step with constant step-size given by $x_{0}$, $x_{1}, \ldots, x_{n-1}, x_{n}, x_{n+1}, \ldots, x_{N}=b$, as displayed in Figure 1. From the same figure, the first block supposedly contains $x_{n-2}, x_{n-1}$ and $x_{n}$ where $x_{n-2}$ will be appointed as the first point while $x_{n}$ will be denoted as the last point. The evaluated solutions in $k^{\text {th }}$ block will be applied as the initial values for $(\mathrm{k}+1)^{\text {th }}$ block. The iteration of the off-step $y_{n+\frac{1}{2}}$ will be approximated first, before calculating $y_{n+1}$ and $y_{n+2}$. The same procedure will be repeated in approximating the next block until reaching the final point of the interval. The purpose of iterating solutions in a block is to reduce the time consumed as the mathematical computation has been decreased.

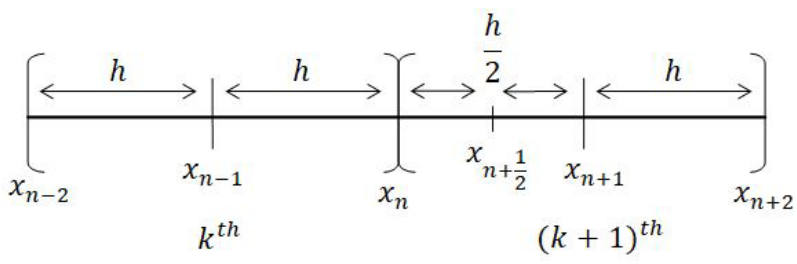

FIGURE 1. Two-point blocks with off-step point

\section{DERIVATION OF METHOD}

Based on Lambert (1973), a linear multistep method formula which incorporates a function evaluation at an off-step point is given by:

$$
\sum_{j=0}^{k} \alpha_{j} y_{n+j}=h \sum_{j=0}^{k} \beta_{j} f_{n+j}+h \beta_{v} f_{n+v},
$$

where $\alpha_{k}=1, \alpha_{0}$ and $\beta_{0}$ are both non-zero, $\mathrm{v} \notin\{0,1, \ldots$, $k\}$ as mentioned in Lambert (1973). In order to develop the proposed off-step block method, a Taylor series interpolation polynomial has been applied as shown in Definition 1 below:

Definition 1 Linear difference operator L associated with (3) is given by:

$\left.L[y(x): h]=\sum_{j=0}^{k} \alpha_{j} y(x+j h)-h \beta_{j} y^{\prime}(x+j h)\right]-h \beta v_{j} y^{\prime}\left(x+v_{j} h\right)$.

Expanding $y(x+j h)$ and $y^{\prime}(x+j h)$ using the Taylor series about $x$ and collecting terms will give:

$$
L[y(x): h]=C_{0} y(x)+C_{1} h y^{(1)}(x)+\ldots+C_{p} h^{p} y^{(p)}(x) .
$$

As mentioned in (1), the expression of $f(x, y(x), y(x-$ $\left.\tau_{i}\right), y^{\prime}\left(x-\sigma_{i}\right)$ which includes both delay and its delay derivative will be evaluated and denoted as $f_{n}$. In the process of developing predictor solutions at $x_{n+\frac{1}{2}}, x_{n+1}$ and $x_{n+2}$, three previous values approximated at $x_{n}, x_{n-1}$ and $x_{n-2}$ have been used. Thus, the approximation of $y\left(x_{n+\frac{1}{2}}\right), \mathrm{y}\left(x_{n+1}\right)$ and $\mathrm{y}\left(x_{n+2}\right)$ in the predictor form when the value of $k=2$ will become:

$y_{n+a}^{p}=\alpha_{0} y_{n+(k-2)}+h \sum_{j=0}^{k} \quad \beta_{j} y^{\prime}[x+(j-k) h]$

where $a$ is denoted as $\frac{(k-1)}{2},(k-1)$ and $k$ for the predictor formula of the off-step, first and second point, respectively, while the corrector form is:

$$
\begin{gathered}
y_{n+(k-1)}^{c}=\alpha_{0} y_{n+(k-2)}+h \sum_{j=0}^{k-1} \quad \beta_{j} y^{\prime}[x+(j-k) h] \\
+h \sum_{j=k+1}^{k+1} \beta_{j} y^{\prime}[x+(j-k) h]+h \beta_{v_{j}} y \\
{\left[x+v_{j} h\right],} \\
y_{n+k}^{c}=\alpha_{0} y_{n+(k-2)}+h \sum_{j=0}^{k-2} \quad \beta_{j} y^{\prime}[x+(j-k) h] \\
+h \sum_{j=k}^{k} \quad \beta_{j} y^{\prime}[x+(j-k) h]+h \sum_{j=k+2}^{k+2} \\
\beta_{j} y^{\prime}[x+(j-k) h] \\
+h \beta_{v_{j}} y^{\prime}\left[x+v_{j} h\right] .
\end{gathered}
$$

By letting $\alpha_{0}=1$, the terms in (6) and (7) are expanded respectively using Taylor series expansion. Also, by substituting the expansion back in (6) and (7), collecting all the terms will give a two-point implicit hybrid multistep block method (2PIH):

$$
\begin{aligned}
y_{n+\frac{1}{2}}^{p} & =y_{n}+\frac{h}{24}\left[17 f_{n}-7 f_{n-1}+2 f_{n-2}\right], \\
y_{n+1}^{p} & =y_{n}+\frac{h}{12}\left[23 f_{n}-16 f_{n-1}+5 f_{n-2}\right], \\
y_{n+2}^{p} & =y_{n}+\frac{h}{3}\left[19 f_{n}-20 f_{n-1}+7 f_{n-2}\right],
\end{aligned}
$$

and

$$
\begin{aligned}
& y_{n+1}^{c}=y_{n}+\frac{h}{90}\left[10 f_{n+1}+76 f_{n+\frac{1}{2}}+5 f_{n-1}-f_{n-2}\right], \\
& y_{n+2}^{c}=y_{n}+\frac{h}{30}\left[15 f_{n+2}+64 f_{n+\frac{1}{2}}-20 f_{n}+f_{n-2}\right] .
\end{aligned}
$$

Numerical method denoted by (8) and (9) will be implemented in solving both constant and pantograph NDDEs.

\section{ORDER OF METHOD}

The order and error constant of the two-point implicit hybrid multistep block method (2PIH) can be obtained by applying Definition 2 as shown:

Definition 2 A modified linear multistep method (3) is said to be of order if the error constants $C_{0}=C_{1}=\ldots=C_{p}$ $=0$ and $C_{p+1} \neq 0$ and, 
$C_{p}=\frac{1}{p !}\left[\sum_{j=1}^{k+1} j^{p} \alpha_{j}-p\left(\sum_{j=1}^{k+1} j^{p-1} \beta_{j}+\sum_{j=1}^{k+1} v_{j}^{p-1} \beta_{j}\right)\right.$.

In determining the order of the proposed method, (9) is reconstructed in matrix form as shown:

$$
\begin{gathered}
{\left[\begin{array}{llllll}
0 & 0 & 0 & -1 & 1 & 0 \\
0 & 0 & 0 & -1 & 0 & 1
\end{array}\right]\left[\begin{array}{c}
y_{n-3} \\
y_{n-2} \\
y_{n-1} \\
y_{n} \\
y_{n+1} \\
y_{n+2}
\end{array}\right]} \\
=h\left[\begin{array}{cccccc}
-\frac{9}{24} & \frac{37}{24} & -\frac{59}{24} & \frac{55}{24} & 0 & 0 \\
0 & -\frac{1}{3} & \frac{4}{3} & -\frac{5}{3} & \frac{8}{3} & 0
\end{array}\right]\left[\begin{array}{c}
f_{n-3} \\
f_{n-2} \\
f_{n-1} \\
f_{n} \\
f_{n+1} \\
f_{n+2}
\end{array}\right]
\end{gathered}
$$

where $\alpha_{0}, \ldots, \alpha_{5}$ and $\beta_{0}, \ldots, \beta_{5}$ and are denoted as follows:

$\alpha_{0}=\left[\begin{array}{l}0 \\ 0\end{array}\right], \alpha_{1}=\left[\begin{array}{l}0 \\ 0\end{array}\right], \alpha_{2}=\left[\begin{array}{l}0 \\ 0\end{array}\right], \alpha_{3}=\left[\begin{array}{l}-1 \\ -1\end{array}\right], \alpha_{4}=\left[\begin{array}{l}1 \\ 0\end{array}\right], \alpha_{5}=\left[\begin{array}{l}0 \\ 1\end{array}\right]$,

$\beta_{0}=\left[\begin{array}{c}-\frac{9}{24} \\ 0\end{array}\right], \beta_{1}=\left[\begin{array}{c}\frac{37}{24} \\ -\frac{1}{3}\end{array}\right], \beta_{2}=\left[\begin{array}{c}-\frac{59}{24} \\ \frac{4}{3}\end{array}\right], \beta_{3}=\left[\begin{array}{c}\frac{55}{24} \\ -\frac{5}{3}\end{array}\right], \beta_{4}=\left[\begin{array}{l}0 \\ \frac{8}{3}\end{array}\right], \beta_{5}=\left[\begin{array}{l}0 \\ 0\end{array}\right]$.

Thus, according to Lambert (1973), Definition 2 is applied:

$$
\begin{aligned}
& C_{0}=\sum_{j=0}^{k+1} \quad \alpha_{j}=\left[\begin{array}{l}
0 \\
0
\end{array}\right], \\
& C_{1}=\sum_{j=0}^{k+1} \quad j \alpha_{j}-\sum_{j=0}^{k+1} \quad \beta_{j}-\sum_{j=1}^{1} \quad v_{j} \beta_{j}=\left[\begin{array}{l}
0 \\
0
\end{array}\right], \\
& C_{2}=\frac{1}{2 !}\left[\begin{array}{llll}
\sum_{j=1}^{k+1} & j^{2} \alpha_{j}-2\left(\sum_{j=1}^{k+1}\right. & j \beta_{j}+\sum_{j=1}^{1} & \left.v_{j} \beta_{j}\right)
\end{array}\right]=\left[\begin{array}{l}
0 \\
0
\end{array}\right], \\
& C_{3}=\frac{1}{3 !}\left[\begin{array}{llll}
\sum_{j=1}^{k+1} & j^{3} \alpha_{j}-3\left(\sum_{j=1}^{k+1}\right. & j^{2} \beta_{j}+\sum_{j=1}^{1} & \left.v_{j}^{2} \beta_{j}\right)
\end{array}\right]=\left[\begin{array}{l}
0 \\
0
\end{array}\right], \\
& C_{4}=\frac{1}{4 !}\left[\begin{array}{llll}
\sum_{j=1}^{k+1} & j^{4} \alpha_{j}-4\left(\sum_{j=1}^{k+1}\right. & j^{3} \beta_{j}+\sum_{j=1}^{1} & \left.v_{j}^{3} \beta_{j}\right)
\end{array}\right]=\left[\begin{array}{l}
0 \\
0
\end{array}\right], \\
& C_{5}=\frac{1}{5 !}\left[\begin{array}{llll}
\sum_{j=1}^{k+1} & j^{5} \alpha_{j}-5\left(\sum_{j=1}^{k+1}\right. & j^{4} \beta_{j}+\sum_{j=1}^{1} & \left.v_{j}^{4} \beta_{j}\right)
\end{array}\right]=\left[\begin{array}{c}
\frac{19}{2880} \\
-\frac{17}{180}
\end{array}\right] .
\end{aligned}
$$

This implies that the block method has order four with error constant $C_{p+1}=C_{5}=\left[\begin{array}{c}\frac{19}{2880} \\ -\frac{17}{180}\end{array}\right]$. In the development of numerical solutions for solving differential equations, it is well known that the order of a certain method plays an important role in determining its accuracy.

\section{CONSISTENCY OF METHOD}

The property of consistency for multistep method has been mentioned by Lambert (1973) as shown below:

Definition 3 A linear multistep method (3) is said to be consistent if it has order and only if:

$$
\sum_{j=0}^{k} \alpha_{j}=\left[\begin{array}{l}
0 \\
0
\end{array}\right] \text { and } \sum_{j=0}^{k} j \alpha_{j}=\sum_{j=0}^{k} \beta_{j} .
$$

Based on Definition 2, 2PIH is a method of order four and is shown to satisfy both conditions and. Thus, the block method is said to be consistent. If $2 \mathrm{PIH}$ is consistent, the performance of the method is predicted to be better in any type of real problems.

\section{CONVERGENCE ANALYSIS}

The section is dedicated to prove the convergence of the proposed method as the steps are getting smaller. The convergence of $2 \mathrm{PIH}$ can be proved through mathematical procedure shown below:

Theorem 1 Let $f(x, y)$ be defined as continuous for all points in the region defined by $\mathrm{a} \leq \mathrm{x} \leq \mathrm{b},-\infty<\mathrm{y}<\infty$, $\mathrm{a}$ and $\mathrm{b}$ finite, and let there exist a constant such that for every $x, y, y^{*}$ such that $(x, y)$ and $\left(x, y^{*}\right)$ are both in $\mathrm{D}$,

$$
\left|f(x, y)-f\left(x, y^{*}\right)\right| \leq L\left|y-y^{*}\right|
$$

Equation (13) is known as a Lipschitz condition, and the constant is known as a Lipschitz constant that satisfies 0 $\leq x \leq 1$.

Definition 4 A linear multistep method (3) is said to be convergent if, for all initial value problems subject to the hypotheses of Theorem 1:

$$
\lim _{h \rightarrow 0} y_{n}=y^{*}\left(x_{n}\right)
$$

holds for all, and for all solutions $\left\{y_{n}\right\}$ of the difference (3).

From the corrector formula of (9), where the block method is defined over the interval $x_{0} \leq x \leq x_{N}$ in order to approximate $y_{n+1}^{*}$ and $y^{*}{ }_{n+2}$, respectively. We also have:

$$
\begin{aligned}
& \lim _{h \rightarrow 0} y_{n+1}=y_{n+1}^{*}, \\
& \lim _{h \rightarrow 0} y_{n+2}=y_{n+2}^{*},
\end{aligned}
$$

which is the convergence condition for the approximated solutions.

Let us consider the exact solutions of (9) to be:

$$
\begin{aligned}
y_{n+1}^{*}= & y_{n}^{*}+\frac{h}{90}\left[10 f_{n+1}+76 f_{n+\frac{1}{2}}+5 f_{n-1}-f_{n-2}\right]+ \\
& \frac{19}{2880} h^{5} y^{*(5)}\left(\xi_{n}\right),
\end{aligned}
$$




$$
\begin{aligned}
y_{n+2}^{*}= & y_{n}^{*}+\frac{h}{30}\left[15 f_{n+2}+64 f_{n+\frac{1}{2}}-20 f_{n}+f_{n-2}\right]- \\
& \frac{17}{180} h^{5} y^{*(5)}\left(\xi_{n}\right) .
\end{aligned}
$$

Subtracting (15) and (9) to yield:

$$
\begin{aligned}
y_{n+1}^{*}-y_{n+1} & =\left[y_{n}^{*}+\frac{10 h}{90} f_{n+1}+\frac{76 h}{90} f_{n+\frac{1}{2}}+\frac{5 h}{90} f_{n-1}-\frac{h}{90} f_{n-2}\right] \\
& -\left[y_{n}+\frac{10 h}{90} f_{n+1}+\frac{76 h}{90} f_{n+\frac{1}{2}}+\frac{5 h}{90} f_{n-1}-\frac{h}{90} f_{n-2}\right] \\
& +\frac{19}{2880} h^{5} y^{*(5)}\left(\xi_{n}\right),
\end{aligned}
$$

$$
\begin{aligned}
y_{n+2}^{*}-y_{n+2} & =\left[y_{n}^{*}+\frac{15 h}{30} f_{n+2}+\frac{64 h}{30} f_{n+\frac{1}{2}}-\frac{20 h}{30} f_{n}+\frac{h}{30} f_{n-2}\right] \\
& -\left[y_{n}+\frac{15 h}{30} f_{n+2}+\frac{64 h}{30} f_{n+\frac{1}{2}}-\frac{20 h}{30} f_{n}+\frac{h}{30} f_{n-2}\right] \\
& -\frac{17}{180} h^{5} y^{*(5)}\left(\xi_{n}\right) .
\end{aligned}
$$

Expanding (15) will produce:

$$
\begin{aligned}
y_{n+1}^{*} & -y_{n+1}=y_{n}^{*}-y_{n}+\frac{10 h}{90}\left[f\left(x_{n+1}, y_{n+1}^{*}, y_{\alpha(n+1)}^{*}, y_{\alpha(n+1)}^{*}\right)\right. \\
& \left.-f\left(x_{n+1}, y_{n+1}, y_{\alpha(n+1)}, y_{\alpha(n+1)}^{\prime}\right)\right]+\frac{76 h}{90} \\
& {\left[f\left(x_{n+\frac{1}{2}}, y_{n+\frac{1}{2}}^{*} y_{\alpha\left(n+\frac{1}{2}\right)}^{*} y_{\alpha\left(n+\frac{1}{2}\right)}^{*}\right)-f\left(x_{n+\frac{1}{2}}, y_{n+\frac{1}{2}}, y_{\alpha\left(n+\frac{1}{2}\right)}, y_{\alpha\left(n+\frac{1}{2}\right)}^{\prime}\right)\right] } \\
& +\frac{5 h}{90}\left[f\left(x_{n-1}, y_{n-1}^{*}, y_{\alpha(n-1)}^{*}, y_{\alpha(n-1)}^{*}\right)-f\left(x_{n-1}, y_{n-1}, y_{\alpha(n-1)}, y_{\alpha(n-1)}^{\prime}\right)\right] \\
& +\frac{h}{90}\left[f\left(x_{n-2}, y_{n-2}, y_{\alpha(n-2)}, y_{\alpha(n-2)}^{\prime}\right)-f\left(x_{n-2}, y_{n-2}^{*}, y_{\alpha(n-2)}^{*}, y_{\alpha(n-2)}^{*}\right)\right] \\
& +\frac{19}{2880} h^{5} y^{*(5)}\left(\xi_{n}\right),
\end{aligned}
$$

and

$$
\begin{aligned}
& y_{n+2}^{*}-y_{n+2}=y_{n}^{*}-y_{n}+\frac{15 h}{30}\left[f\left(x_{n+2}, y_{n+2}^{*}, y_{\alpha(n+2)}^{*}, y_{\alpha(n+2)}^{*}\right)\right. \\
& \left.-f\left(x_{n+2}, y_{n+2}, y_{\alpha(n+2)}, y_{\alpha(n+2)}^{\prime}\right)\right]+\frac{64 h}{30} \\
& {\left[f\left(x_{n+\frac{1}{2}}, y_{n+\frac{1}{2}}^{*}, y_{\alpha\left(n+\frac{1}{2}\right)}^{*}, y_{\alpha\left(n+\frac{1}{2}\right)}^{y^{*}}\right)-f\left(x_{n+\frac{1}{2}}, y_{n+\frac{1}{2}}, y_{\alpha\left(n+\frac{1}{2}\right)}, y_{\alpha\left(n+\frac{1}{2}\right)}^{\prime}\right)\right]} \\
& +\frac{20 h}{30}\left[f\left(x_{n}, y_{n}, y_{\alpha(n)}, y_{\alpha(n)}^{\prime}\right)-f\left(x_{n}, y_{n}^{*}, y_{\alpha(n)}^{*}, y_{\alpha(n)}^{*}\right)\right] \\
& +\frac{h}{30}\left[f\left(x_{n-2}, y_{n-2}^{*}, y_{\alpha(n-2)}^{*}, y_{\alpha(n-2)}^{*}\right)-f\left(x_{n-2}, y_{n-2}, y_{\alpha(n-2)}, y_{\alpha(n-2)}^{\prime}\right)\right] \\
& -\frac{17}{180} h^{5} y^{*(5)}\left(\xi_{n}\right) \text {. }
\end{aligned}
$$

Denote the numerical difference, $d_{n}=y_{n}^{*}-y_{n}$, then taking the absolute norm for both sides and applying the triangle inequalities, we have the following bound:

$$
\begin{aligned}
\left|d_{n+1}\right| & \leq\left|d_{n}\right|+\frac{10 h}{90} L\left|d_{n+1}\right|+\frac{76 h}{90} L\left|d_{n+\frac{1}{2}}\right|+\frac{5 h}{90} L\left|d_{n-1}\right|+\frac{h}{90} L\left|d_{n-2}\right| \\
& +\frac{19 h}{2880} h^{5} y^{*(5)}\left(\xi_{n}\right), \\
\left|d_{n+2}\right| & \leq\left|d_{n}\right|+\frac{15 h}{30} L\left|d_{n+2}\right|+\frac{64 h}{30} L\left|d_{n+\frac{1}{2}}\right|+\frac{20 h}{30} L\left|d_{n}\right|+\frac{h}{30} L\left|d_{n-2}\right| \\
& +\frac{17}{180} h^{5} y^{*(5)}\left(\xi_{n}\right) .
\end{aligned}
$$

By applying Theorem 1 which is equivalent to first-order differential equation $f(x, y)=y^{\prime}(x, y)$, which is based on Süli and Mayers (2003),

$\left|y_{n}^{*}-y_{n}^{\prime}\right|=\left|f\left(x_{n}, y_{n}^{*}, y_{\alpha(n)}^{*}, y_{\alpha(n)}^{*}\right)-f\left(x_{n}, y_{n}, y_{\alpha(n)}, y_{\alpha(n)}^{\prime}\right)\right| \leq L\left|d_{n}\right|,(20)$

where $y_{\alpha(\mathrm{n})}^{*}$ is the delay term. Assume that there exist a bound for $\left|y^{*(5)}(x)\right|$ which we called as $B$ so that

$$
\begin{aligned}
& \left(1-\frac{10 h}{90} L\right) \quad\left|d_{n+1}\right| \leq\left|d_{n}\right|+\frac{76 h}{90} L\left|d_{n+\frac{1}{2}}\right|+\frac{5 h}{90} L\left|d_{n-1}\right|+\frac{h}{90} L\left|d_{n-2}\right|+\frac{19 h}{2880} h^{5} B, \\
& \left(1-\frac{15 h}{30} L\right) \quad\left|d_{n+2}\right| \leq\left(1-\frac{20 h}{30} L\right)\left|d_{n}\right|+\frac{64 h}{30} L\left|d_{n+\frac{1}{2}}\right|+\frac{h}{30} L\left|d_{n-2}\right|+\frac{17 h}{180} h^{5} B .
\end{aligned}
$$

Thus,

$$
\begin{aligned}
\left|d_{n+1}\right| & \leq\left(\frac{1}{1-\frac{10}{90} h L}\right)\left|d_{n}\right|+\left(\frac{\frac{76}{90} h L}{1-\frac{10}{90} h L}\right)\left|d_{n+\frac{1}{2}}\right|+\left(\frac{\frac{5}{90} h L}{1-\frac{10}{90} h L}\right)\left|d_{n-1}\right| \\
& +\left(\frac{\frac{h L}{90}}{1-\frac{10}{90} h L}\right)\left|d_{n-2}\right|+\left(\frac{\frac{19 h}{2880} h^{5} B}{1-\frac{10 h}{90} L}\right), \\
\left|d_{n+2}\right| & \leq\left(\frac{1-\frac{20}{30} h L}{1-\frac{15}{30} h L}\right)\left|d_{n}\right|+\left(\frac{\frac{64}{30} h L}{1-\frac{15}{30} h L}\right)\left|d_{n+\frac{1}{2}}\right|+\left(\frac{\frac{h L}{30}}{1-\frac{15}{30} h L}\right)\left|d_{n-2}\right| \\
& +\left(\frac{17 h h^{5} B}{1-\frac{15 h}{30} L}\right) .
\end{aligned}
$$

As $h$ tends to zero, then:

$$
\begin{aligned}
& \lim _{h \rightarrow 0} y_{n+1}=y_{n+1}^{*}, \\
& \lim _{h \rightarrow 0} y_{n+2}=y_{n+2}^{*},
\end{aligned}
$$

where condition (13), $\left|d_{n+1}\right| \leq\left|d_{n}\right|$ and $y^{*}{ }_{n+1}-y_{n+1}=y^{*}{ }_{n}$ $-y_{n}$ are satisfied and thus the convergence of the block method is proved.

\section{STABILITY ANALYSIS}

In this section, the stability analysis of 2PIH for NDDEs is presented. The interpretation of stability analysis for NDDEs begins by evaluating NP-stability which has been developed by Bellen et al. (1988). The definition for NP-stability is stated as follows:

Definition 5 For the step size $\mathrm{h}$, if a, b, and c are complex, the region $\mathrm{R}_{\mathrm{NP}}$ in the $\left(\mathrm{H}_{1}, \mathrm{H}_{2}\right)$-plane is called the NPstability region if for any $\left(\mathrm{H}_{1}, \mathrm{H}_{2}\right) \in \mathrm{R}_{\mathrm{NP}}$. The test equation for NP-stability of NDDEs is:

$$
y^{\prime}(x)=a y(x)+b y(x-\tau)+c y^{\prime}(x-\tau)
$$

where $\tau$ is the delay term. The definition of absolute stability for ODEs can also be extended to the method for solving NDDEs. By letting $Y_{N+j}$ and $F_{N+j}$ be defined as vectors, then the block method can be written as:

$$
\sum_{j=0}^{2} A_{j} Y_{N+j}=h \sum_{j=0}^{2} \beta_{j} F_{N+j} .
$$

Equation (23) is then substituted into the corrector formulae of $2 \mathrm{PIH}$ stated in (9) to obtain: 


$$
\begin{gathered}
\sum_{j=0}^{2} A_{j} Y_{N+j} \\
=h \sum_{j=0}^{2} \beta_{j}\left(a Y_{N+j}+b Y_{N+j-m}+c Y_{N+j-m}^{\prime}\right) .
\end{gathered}
$$

By replacing $H_{1}=h a, H_{2}=h b$ and applying (23) into (24) as stated by Ishak et al. (2014) will give:

$$
\begin{aligned}
\sum_{j=0}^{2} A_{j} Y_{N+j}= & H_{1} \sum_{j=0}^{2} B_{j} Y_{N+j}+H_{2} \sum_{j=0}^{2} B_{j} Y_{N+j-m}+c B_{0} Y_{N-m} \\
& +c B_{1} Y_{N+1-m}+c B_{2} Y_{N+2-m} .
\end{aligned}
$$

Rearranging (26):

$$
\sum_{j=0}^{2}\left(A_{j}-H_{1} B_{j}\right) Y_{N+j}=\sum_{j=0}^{2}\left(H_{2} B_{j}+c B_{j}\right) Y_{N+j-m} .
$$

Stability polynomial for (27) is given by:

$$
\begin{aligned}
\pi(t)= & \operatorname{det}\left[\left(A_{0}-B_{0} H_{1}\right) t^{m}+\left(A_{1}-B_{1} H_{1}\right) t^{1+m}\right. \\
& +\left(A_{2}-B_{2} H_{1}\right) t^{2+m}-\left(B_{0} H_{2}-c B_{0}\right) t^{0}- \\
& \left.\left(B_{1} H_{2}+c B_{1}\right) t^{1}-\left(B_{2} H_{2}+c B_{2}\right) t^{2}\right] .
\end{aligned}
$$

The NP-stability region for 2PIH when $m=1$ letting is shown in Figure 2. The NP-stability lies inside the close region given in Figure 2. The boundary of the NPstability region in $H_{1}-H_{2}$ plane has been determined by substituting $t=1,0,-1$ and $e^{\mathrm{i} \theta}$ where $0 \leq \theta \leq 2 \pi$ in stability polynomial (28). The region of stability illustrates suitable step-size used when applying $2 \mathrm{PIH}$ and based on Lambert (1973),

Definition 5 A linear multistep method is said to be absolutely stable if all roots of the stability polynomials are not greater than one $|t|<1$ and is absolutely unstable if $|t|>1$.

Since the set of all roots in stability polynomials obtained for the method are $|t|<1$, the 2PIH is said to be absolute stable.

$\mathrm{H} 2$

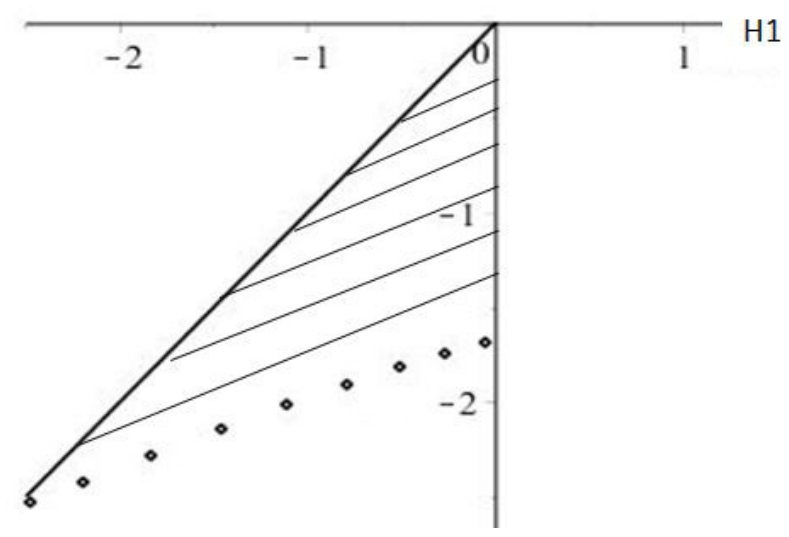

FIGURE 2. NP-stability of $2 \mathrm{PIH}$

\section{IMPLEMENTATION OF METHOD}

The 2PIH that has been formulated based on predictorcorrector formulas in $P E(C E)^{m}$ mode will be applied to approximate the solutions at two-point concurrently including the off-step point with constant step-size. The initial points need to be approximated first before proceeding to the proposed method. In this paper, NDDEs with constant and pantograph delay types are chosen as test problems. The location of the delay must be determined to obtain the solution of $y(x-\tau)$ and $y(q x)$. For constant delay, if $x-\tau_{i}<a$, then the initial function in (1) needs to be applied. If $x-\tau_{i} \geq a$, then any previous solutions of the iteration can be used as the approximation values since the delay will always fall on the previous iteration for constant delay case. As for pantograph delay case, most of the delay terms need to be approximated using Lagrange interpolating polynomial:

$P(x)=L_{n, 0}(x) f\left(x_{0}\right)+\cdots+L_{n, n}(x) f\left(x_{n}\right)=\sum_{k=0}^{n} f\left(x_{k}\right) L_{n, k}(x)$,

where

$$
L_{n, k}(x)=\prod_{\substack{i=0 \\ i \neq k}}^{n} \frac{\left(x-x_{i}\right)}{\left(x_{k}-x_{i}\right)}, \quad k=0,1, \ldots, n .
$$

since the delay will not fall on the previous iteration. The derivatives of the delay terms, $y^{\prime}\left(\mathrm{x}-\sigma_{i}\right)$ and $y^{\prime}(q x)$ will be approximated by applying the backward and forward divided difference formulas depending on the availability of the points calculated. Runge-Kutta order 4 (RK4) has been applied to approximate the initial values of constant delay while an implicit Euler method has been used to solve NDDEs with pantograph delay type. Some constraints have caused the used of lower order method in finding the initial values for pantograph delay type. The first constraint is caused by the application of the polynomial since the order of the Lagrange applied is low at the beginning of the iteration and the points are not enough to be calculated in higher order Lagrange polynomial. Thus, any higher order method applied will have restriction as the used of Lagrange interpolating polynomial needs to be approximated using many points in order to obtain an accurate result. The second constraint is that the Lagrange polynomial is being applied more than once in one iteration and causing the results to become less accurate. The proposed method, $2 \mathrm{PIH}$ in the form of predictor-corrector mode will produce the approximations $y_{n+\frac{1}{2}}^{p}, y_{n+1}^{p}, y_{n+2}^{p}, y_{n+1}^{c}$ and $y_{n+2}^{c}$ simultaneously. The off-step point will first be approximated before proceeding to the predictorcorrector mode. After obtaining the half point, the predictor formula will predict the first solution of every iteration and the value obtained will be substituted into the corrector formula. Thus, the solutions obtained from the corrector will then be iterated until the corrected value converges. 


\section{ALGORITHM OF CONSTANT NDDEs}

Step 1: Set the values of $x_{0}=\alpha, x_{n}=b, h, N, y_{0}, y^{\prime}(x-\tau)$ $\leq a$

Step 2: Define the differential equation:

$$
y^{\prime}(x)=f\left(x, y(x), y\left(x-\tau_{i}\right), y^{\prime}\left(x-\sigma_{i}\right)\right)
$$

Step 3: If $x-\tau \leq a$, then the function given in (1) is used.

Step 4: If If $x-\tau \geq a$, then Lagrange interpolating polynomial (29) is applied.

Step 5: For $n=0,1$,

RK4 is applied to compute the starting values and the backward divided difference is applied to find $y^{\prime}(x-\tau)$.

Step 6: For $n=2,4,6, \ldots$,

The first and second point of 2PIH4 is used to approximate NDDEs:

$y_{n+\frac{1}{2}}^{p}=y_{n}+\frac{h}{24}\left[17 f_{n}-7 f_{n-1}+2 f_{n-2}\right]$,

$y_{n+1}^{p}=y_{n}+\frac{h}{12}\left[23 f_{n}-16 f_{n-1}+5 f_{n-2}\right]$,

$y_{n+2}^{p}=y_{n}+\frac{h}{3}\left[19 f_{n}-20 f_{n-1}+7 f_{n-2}\right]$,

$y_{n+1}^{c}=y_{n}+\frac{h}{90}\left[10 f_{n+1}+76 f_{n+\frac{1}{2}}+5 f_{n-1}-f_{n-2}\right]$,

$y_{n+2}^{c}=y_{n}+\frac{h}{30}\left[15 f_{n+2}+64 f_{n+\frac{1}{2}}-20 f_{n}+f_{n-2}\right]$.

Forward divided difference is applied to find $y^{\prime}(x-\tau)$.

Step 7: The corrector formula is iterated twice.

Step 8: Maximum and average error, total steps taken, function calls and central processing unit (CPU) time required are computed.

Step 9: Stop

\section{ALGORITHM OF PANTOGRAPH NDDEs}

Step 1: Set the values of $x_{0}=\alpha, x_{n}=b, h, N, y_{0}$.

Step 2: Define the differential equation:

$y^{\prime}(x)=f\left(x, y(x), y(q x), y^{\prime}(q x)\right.$

Step 3: If $y(q x)$ which is the delay term, falls exactly on the previous solution, then the initial solutions given in (2) will be applied directly.

Step 4: If $y(q x)$ does not fall on any previous computed solution, then the delay terms will be solved by applying Lagrange interpolating polynomial stated in (29).

Step 5: $\quad$ For $n=0,1$,

Implicit Euler is applied to compute the starting values and backward divided difference is applied to find $y^{\prime}(q x)$

Step 6: For $n=2,4,6, \ldots$,
The first and second point of 2PIH4 is used to approximate NDDEs

$$
\begin{aligned}
& y_{n+\frac{1}{2}}^{p}=y_{n}+\frac{h}{24}\left[17 f_{n}-7 f_{n-1}+2 f_{n-2}\right], \\
& y_{n+1}^{p}=y_{n}+\frac{h}{12}\left[23 f_{n}-16 f_{n-1}+5 f_{n-2}\right], \\
& y_{n+2}^{p}=y_{n}+\frac{h}{3}\left[19 f_{n}-20 f_{n-1}+7 f_{n-2}\right], \\
& y_{n+1}^{c}=y_{n}+\frac{h}{90}\left[10 f_{n+1}+76 f_{n+\frac{1}{2}}+5 f_{n-1}-f_{n-2}\right], \\
& y_{n+2}^{c}=y_{n}+\frac{h}{30}\left[15 f_{n+2}+64 f_{n+\frac{1}{2}}-20 f_{n}+f_{n-2}\right] .
\end{aligned}
$$

Forward divided difference is applied to find $y^{\prime}(q x)$.

Step 7: Maximum and average error, total steps taken, function calls and central processing unit (CPU) time required are computed.

Step 8: Stop

\section{RESULTS AND DISCUSSION}

Some numerical results for 2PIH4 have been presented in this section to show the efficiency and applicability of the block method in solving NDDEs. Five problems for first order NDDEs of constant and pantograph types have been tested. Examples 1, 4, and 5 are taken from Ishak et al. (2014) while the second and third examples are taken from Ishak and Ramli (2015).

The following notations involved are summarized in Tables 1-5:

MTD : Method

FCN : Total function calls

TS : Total Step

TIME(s) : Time Taken (Seconds)

MAXE : Maximum Error

AVERE : Average Error

2PIH4 : Two-point Implicit Hybrid Multistep Block Method of Order 4

2P1B4 : Two-point Block Method Order 4 (Seong \& Majid 2015)

2PEBM4 : Two-point Explicit Multistep Block Method of Order 4 (Ismail et al. 2019)

ABM4 : Adam Bashforth Moulton of Order 4

RK4 : Runge Kutta of Order 4

Example 1 (Constant delay, $\tau=1$ average cell-division time)

$$
\begin{array}{ll}
y^{\prime}(x)=y(x)+y(x-1)-\frac{1}{4} y^{\prime}(x-1), & x \in[0,1] \\
y(x)=-x, & x \leq 0
\end{array}
$$

The exact solution is:

$$
y(x)=-\frac{1}{4}+x+\frac{1}{4} e^{x}
$$


Example 2 (Constant delay, the commitment to the process of cell-division's rate)

$$
\begin{array}{ll}
y^{\prime}(x)=y(x)+y(x-1)-\frac{1}{4} y^{\prime}(x-1)+\sin (x), & x \in[0,1] \\
y(x)=1, & x \leq 0
\end{array}
$$

The exact solution is:

$$
y(x)=-\frac{1}{4}+x+\frac{3}{4} e^{x}-\frac{1}{2} \cos (x)-\frac{1}{2} \sin (x)
$$

Example 3 (Constant delay, $0 \leq p 2 \leq 2=$ the gradual dispersal of cell division synchronization)

$$
\begin{aligned}
& y^{\prime}(x)=y(x)+y^{\prime}(x-1) \\
& y(x)=1,
\end{aligned}
$$$$
x \in[0,1]
$$$$
x \leq 0
$$

The exact solution is:

$$
y(x)=e^{x}
$$

Example 4 (Pantograph delay, the cell-death's rate)

$$
\begin{array}{ll}
y^{\prime}(x)=-y(x)+\frac{1}{2} y\left(\frac{x}{2}\right)+\frac{1}{2} y^{\prime}\left(\frac{x}{2}\right), & x \in[0,1] \\
y(0)=1, & x \leq 0
\end{array}
$$

The exact solution is:

$$
y(x)=e^{-x}
$$

Example 5 (Pantograph delay, the cell-death's rate)

$$
\begin{array}{ll}
y^{\prime}(x)=-y(x)+\frac{1}{10} y\left(\frac{4}{5} x\right)+\frac{1}{2} y^{\prime}\left(\frac{4}{5} x\right)+\left(\frac{8}{25} x-\frac{1}{2}\right) e^{-\frac{4}{5} x}+e^{-x}, & x \in[0,1] \\
y(0)=0, & x \leq 0
\end{array}
$$

The exact solution is:

$$
y(x)=x e^{-x}
$$

Numerical results of 2PIH4 for Example 1-5 with different step-size, number of function call, total step, time taken, average and maximum error are summarized in Tables 1-5, respectively. The algorithms have been implemented using $\mathrm{C}$ language with constant step-size. The 2PIH4 have been compared with two-point block method of order 4 (2P1B4) by Seong and Majid (2015), two-point explicit multistep block method of order 4 (2PEBM4) by Ismail et al. (2019) and Adam Bashforth Moulton of order 4 (ABM4) to show the accuracy and reliability of the proposed implicit hybrid multistep block method in solving NDDEs. From the numerical results obtained in Table 1, it is observed that the average error of 2PIH4 is smaller than that with 2P1B4, 2PEBM4 and ABM4 for every step size used. In Table 2, the smallest average error of 2PIH4 has suggested that this method outperformed others used in the comparison. In terms of total step taken, 2PIH4, 2P1B4 and 2PEBM4 took lesser steps than ABM4 since they are calculated in block. 2PIH4 is iterated twice but still be able to show the same number of total function call with ABM4. The 2PIH4 requires less CPU time to estimate the solutions for NDDEs problems compared to that of ABM4.

For Examples 4 and 5, as the behavior of pantograph delay is quite unique; it has to be handled carefully. Pantograph delay needs to be solved by using lower order method as its initial solutions as explained previously in the implementation section. This is because, it needs to cope with the number of points taken in Lagrange interpolating polynomial to approximate the delay values. After obtaining all the points needed for Lagrange polynomial to complete its appropriate order, then any higher order method can be applied. Thus, the initial solution applied for solving pantograph delay is an implicit Euler method since Euler is a lower order method. The 2PIH4 has lesser functions evaluated than 2P1B4 since it is a fully multistep block method. It has also been clearly shown that the MAXE and AVERE of 2PIH4 are becoming more accurate as the step-size decreases. The order of convergence has been calculated for all five problems. Example 1, 2, and 3 have produced fourth order accuracy while Examples 4 and 5 are not in the same agreement as the previous problems. The situation occurred since Example 4 and 5 are pantograph delay problems which need a different implementation and have been stated in Steps 3 and Step 4 where Lagrange interpolating polynomial is involved. Step 4 will only apply on pantograph problem since the delay for constant NDDE problem has always fallen on the previous solution calculated. The behavior of pantograph delay need to be handled carefully which have resulted in the order barrier. The delay is being estimated with lower order Lagrange interpolating polynomial from the first iteration, thus the consistency and accuracy of the proposed method is affected. An Implicit Euler as the starting method is chosen based on the order of the Lagrange interpolating polynomial to create a comparable calculation in producing better results. From the numerical results for RK4, it is proven that by using a higher order method for the initial will produce less accurate results since the order of the Lagrange interpolating polynomial at the beginning of the iteration is low and it is not suitable to be paired with a higher order method. The smoothness of 2PIH4 has been proved as the average and maximum errors are comparable than 2P1B4, 2PEBM4, ABM4 and better than RK4. The average and maximum errors are the differences between the exact solutions given and the approximate solutions of 2PIH4. As the differences are getting smaller, it is apparent that the proposed numerical method converges. The 2PIH4 is very efficient in reducing total step taken, CPU time and the number of function calls evaluated for the method. 
TABLE 1. Numerical results for Example 1

\begin{tabular}{|c|c|c|c|c|c|c|}
\hline $\mathrm{h}$ & MTD & $\mathrm{FCN}$ & $\mathrm{TS}$ & TIME(s) & MAXE & AVERE \\
\hline \multirow{6}{*}{0.1} & 2PIH4 & 17 & 6 & 0.203 & $1.5916 \mathrm{e}-06$ & $8.7720 \mathrm{e}-07$ \\
\hline & 2P1B4 & 25 & 6 & 0.208 & $1.9350 \mathrm{e}-05$ & $6.5537 \mathrm{e}-06$ \\
\hline & 2PEBM4 & 17 & 6 & 0.125 & $8.7145 \mathrm{e}-06$ & $3.9217 \mathrm{e}-06$ \\
\hline & ABM4 & 17 & 10 & 0.211 & $5.4455 \mathrm{e}-06$ & $1.9983 \mathrm{e}-06$ \\
\hline & RK4 & 41 & 10 & 0.281 & $5.2108 \mathrm{e}-07$ & $2.1846 \mathrm{e}-07$ \\
\hline & 2PIH4 & 107 & 51 & 0.250 & $1.1572 \mathrm{e}-10$ & 7.6466e-11 \\
\hline \multirow[t]{5}{*}{0.01} & 2P1B4 & 205 & 51 & 0.226 & $2.8598 \mathrm{e}-09$ & $1.0446 \mathrm{e}-09$ \\
\hline & 2PEBM4 & 107 & 51 & 0.183 & $1.0874 \mathrm{e}-09$ & $4.0760 \mathrm{e}-10$ \\
\hline & ABM4 & 107 & 100 & 0.257 & $7.5051 \mathrm{e}-10$ & $2.7616 \mathrm{e}-10$ \\
\hline & RK4 & 401 & 100 & 0.312 & $5.6161 \mathrm{e}-11$ & $2.0942 \mathrm{e}-11$ \\
\hline & 2PIH4 & 1007 & 501 & 0.327 & $1.0873 \mathrm{e}-14$ & $7.2399 \mathrm{e}-15$ \\
\hline \multirow[t]{4}{*}{0.001} & 2P1B4 & 2005 & 501 & 0.328 & $2.9732 \mathrm{e}-13$ & $1.0918 \mathrm{e}-13$ \\
\hline & 2PEBM4 & 1007 & 501 & 0.245 & $1.0969 \mathrm{e}-13$ & $4.0193 \mathrm{e}-14$ \\
\hline & ABM4 & 1007 & 1000 & 0.359 & $7.5051 \mathrm{e}-14$ & $2.8391 \mathrm{e}-14$ \\
\hline & RK4 & 4001 & 1000 & 0.422 & $8.6597 \mathrm{e}-15$ & $2.6125 \mathrm{e}-15$ \\
\hline
\end{tabular}

TABLE 2. Numerical results for Example 2

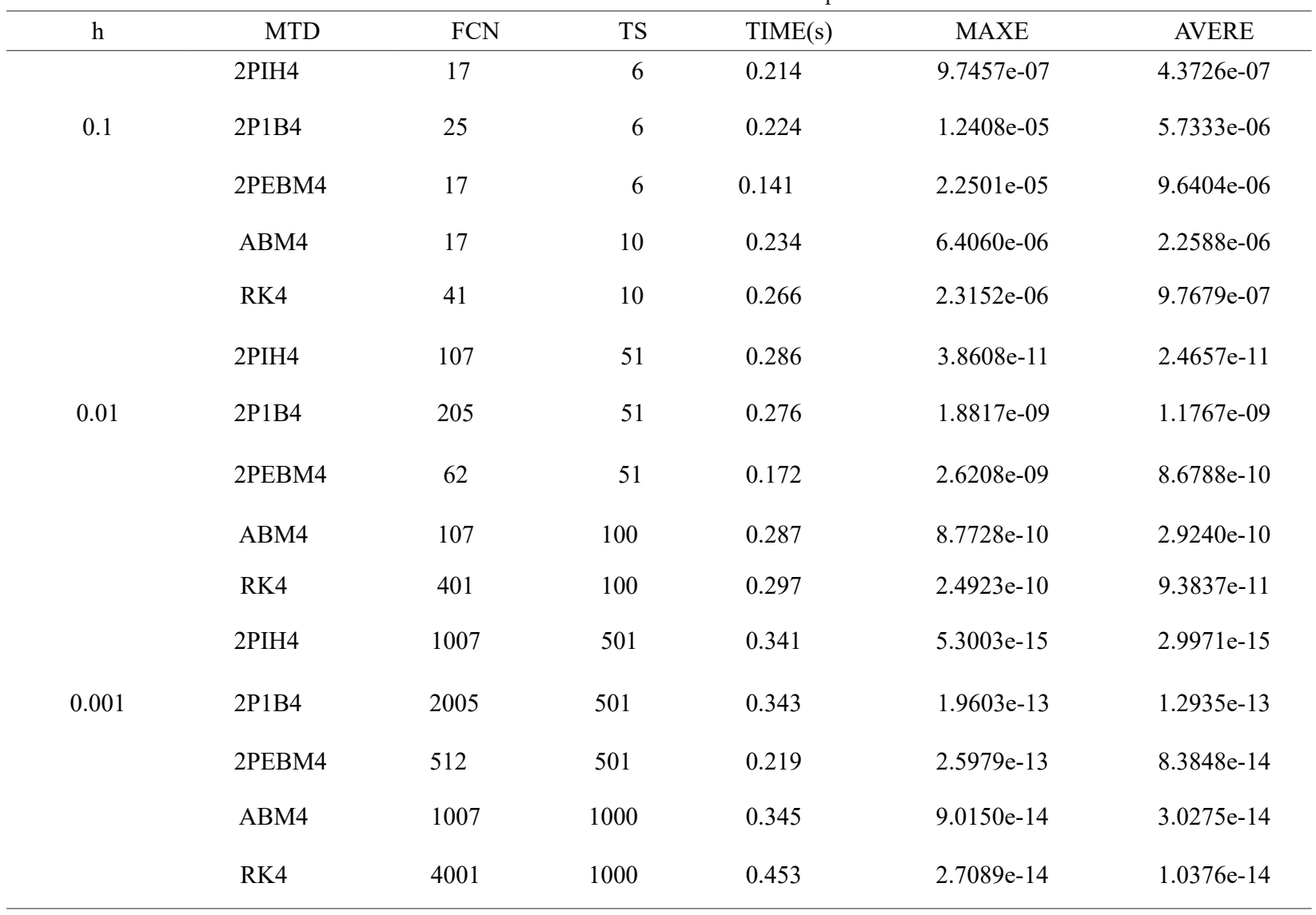


TABLE 3. Numerical results for Example 3

\begin{tabular}{|c|c|c|c|c|c|c|}
\hline $\mathrm{h}$ & MTD & FCN & TS & TIME(s) & MAXE & AVERE \\
\hline & 2PIH4 & 17 & 6 & 0.218 & $3.3481 \mathrm{e}-06$ & $1.6143 \mathrm{e}-06$ \\
\hline \multirow[t]{5}{*}{0.1} & 2P1B4 & 25 & 6 & 0.224 & $7.7401 \mathrm{e}-05$ & $2.6215 \mathrm{e}-05$ \\
\hline & 2PEBM4 & 17 & 6 & 0.125 & $3.4858 \mathrm{e}-05$ & $1.5687 \mathrm{e}-05$ \\
\hline & ABM4 & 17 & 10 & 0.238 & $2.1782 \mathrm{e}-05$ & $7.9931 \mathrm{e}-06$ \\
\hline & RK4 & 41 & 10 & 0.266 & $2.0843 \mathrm{e}-06$ & $8.7383 \mathrm{e}-07$ \\
\hline & 2PIH4 & 107 & 51 & 0.239 & $2.4299 \mathrm{e}-10$ & $1.2228 \mathrm{e}-10$ \\
\hline \multirow[t]{5}{*}{0.01} & 2P1B4 & 205 & 51 & 0.249 & $1.1439 \mathrm{e}-08$ & $4.1785 \mathrm{e}-09$ \\
\hline & 2PEBM4 & 62 & 51 & 0.140 & $4.3497 \mathrm{e}-09$ & $1.6304 \mathrm{e}-09$ \\
\hline & ABM4 & 107 & 100 & 0.260 & $3.0020 \mathrm{e}-09$ & $1.1046 \mathrm{e}-09$ \\
\hline & RK4 & 401 & 100 & 0.281 & $2.2464 \mathrm{e}-10$ & $8.3768 \mathrm{e}-11$ \\
\hline & 2PIH4 & 1007 & 501 & 0.318 & $2.3549 \mathrm{e}-14$ & $1.1941 \mathrm{e}-14$ \\
\hline \multirow[t]{4}{*}{0.001} & 2P1B4 & 2005 & 501 & 0.314 & $1.1928 \mathrm{e}-12$ & $4.3840 \mathrm{e}-13$ \\
\hline & 2PEBM4 & 512 & 501 & 0.213 & $4.3832 \mathrm{e}-13$ & $1.6201 \mathrm{e}-13$ \\
\hline & ABM4 & 1007 & 1000 & 0.317 & $3.1530 \mathrm{e}-13$ & $1.1651 \mathrm{e}-13$ \\
\hline & RK4 & 4001 & 1000 & 0.406 & $2.0428 \mathrm{e}-14$ & $7.4982 \mathrm{e}-15$ \\
\hline
\end{tabular}

TABLE 4. Numerical results for Example 4

\begin{tabular}{|c|c|c|c|c|c|c|}
\hline $\mathrm{h}$ & MTD & $\mathrm{FCN}$ & $\mathrm{TS}$ & TIME(s) & MAXE & AVERE \\
\hline \multirow{5}{*}{0.1} & 2PIH4 & 7 & 6 & 0.206 & $1.7045 \mathrm{e}-04$ & $1.6925 \mathrm{e}-04$ \\
\hline & 2P1B4 & 16 & 6 & - & $1.9293 \mathrm{e}-04$ & $1.9293 \mathrm{e}-04$ \\
\hline & 2PEBM4 & 7 & 7 & 0.156 & $2.1288 \mathrm{e}-04$ & $1.9838 \mathrm{e}-04$ \\
\hline & ABM4 & 11 & 10 & 0.245 & $1.4928 \mathrm{e}-04$ & $1.5563 \mathrm{e}-04$ \\
\hline & RK4 & 41 & 10 & 0.250 & $1.9899 \mathrm{e}-02$ & $4.3734 \mathrm{e}-02$ \\
\hline \multirow{5}{*}{0.01} & 2PIH4 & 52 & 51 & 0.214 & $1.2737 \mathrm{e}-07$ & $2.0647 \mathrm{e}-07$ \\
\hline & 2P1B4 & 148 & 51 & - & $4.4494 \mathrm{e}-07$ & $4.4494 \mathrm{e}-07$ \\
\hline & 2PEBM4 & 52 & 52 & 0.177 & $1.8635 \mathrm{e}-07$ & $3.0314 \mathrm{e}-07$ \\
\hline & ABM4 & 101 & 100 & 0.260 & $1.2516 \mathrm{e}-07$ & $2.0483 \mathrm{e}-07$ \\
\hline & RK4 & 401 & 100 & 0.297 & $3.2283 \mathrm{e}-03$ & $7.3136 \mathrm{e}-03$ \\
\hline \multirow{5}{*}{0.001} & 2PIH4 & 502 & 501 & 0.245 & $1.2310 \mathrm{e}-10$ & $2.1028 \mathrm{e}-10$ \\
\hline & 2P1B4 & 1498 & 501 & - & $2.2831 \mathrm{e}-09$ & $2.2831 \mathrm{e}-09$ \\
\hline & 2PEBM4 & 502 & 502 & 0.192 & $1.8418 \mathrm{e}-10$ & $3.1475 \mathrm{e}-10$ \\
\hline & ABM4 & 1001 & 1000 & 0.281 & $1.2288 \mathrm{e}-10$ & $2.1011 \mathrm{e}-10$ \\
\hline & RK4 & 4001 & 1000 & 0.375 & $1.0785 \mathrm{e}-03$ & $5.1841 \mathrm{e}-04$ \\
\hline
\end{tabular}


TABLE 5. Numerical results for Example 5

\begin{tabular}{|c|c|c|c|c|c|c|}
\hline $\mathrm{h}$ & MTD & $\mathrm{FCN}$ & TS & TIME(s) & MAXE & AVERE \\
\hline \multirow{6}{*}{0.1} & 2PIH4 & 7 & 6 & 0.221 & $2.8515 \mathrm{e}-04$ & $2.7298 \mathrm{e}-04$ \\
\hline & 2P1B4 & 16 & 6 & - & $8.5246 \mathrm{e}-03$ & $6.9255 \mathrm{e}-06$ \\
\hline & 2PEBM4 & 7 & 7 & 0.171 & $3.0714 \mathrm{e}-04$ & $3.0912 \mathrm{e}-04$ \\
\hline & ABM4 & 11 & 10 & 0.255 & $2.0221 \mathrm{e}-04$ & $2.2834 \mathrm{e}-04$ \\
\hline & RK4 & 41 & 10 & 0.266 & $4.0247 \mathrm{e}-02$ & $2.7259 \mathrm{e}-03$ \\
\hline & 2PIH4 & 52 & 51 & 0.250 & $1.9338 \mathrm{e}-07$ & $3.1220 \mathrm{e}-07$ \\
\hline \multirow[t]{5}{*}{0.01} & 2P1B4 & 148 & 51 & - & $2.5327 \mathrm{e}-04$ & $1.0546 \mathrm{e}-07$ \\
\hline & 2PEBM4 & 52 & 52 & 0.187 & $2.7914 \mathrm{e}-07$ & $4.5532 \mathrm{e}-07$ \\
\hline & ABM4 & 101 & 100 & 0.271 & $1.8584 \mathrm{e}-07$ & $3.0654 \mathrm{e}-07$ \\
\hline & RK4 & 401 & 100 & 0.344 & $1.9778 \mathrm{e}-02$ & $2.5258 \mathrm{e}-02$ \\
\hline & 2PIH4 & 502 & 501 & 0.281 & $1.8488 \mathrm{e}-10$ & $3.1568 \mathrm{e}-10$ \\
\hline \multirow[t]{4}{*}{0.001} & 2P1B4 & 1498 & 501 & - & $4.0516 \mathrm{e}-06$ & $5.1520 \mathrm{e}-10$ \\
\hline & 2PEBM4 & 502 & 502 & 0.203 & $2.7624 \mathrm{e}-10$ & $4.7219 \mathrm{e}-10$ \\
\hline & ABM4 & 1001 & 1000 & 0.296 & $1.8413 \mathrm{e}-10$ & $3.1510 \mathrm{e}-10$ \\
\hline & RK4 & 4001 & 1000 & 0.437 & $2.1540 \mathrm{e}-02$ & $2.3759 \mathrm{e}-02$ \\
\hline
\end{tabular}

\section{CONCLUSION}

In this paper, first order single linear NDDEs with constant and pantograph delay types have been solved by implementing 2PIH4. The block method has solved NDDEs problems by producing two approximations including the off point in a single step using the same previous values and have shown to reduce the number of function call and CPU time required to complete the computation as compared to 2P1B4 and ABM4. A block method has always produced lesser total step compared to multi-step and one-step method. The numerical results indicate that 2PIH4 is proved to be efficient and suitable to be applied in NDDEs problem with constant and pantograph delay type.

\section{ACKNOWLEDGEMENTS}

The authors are most gratefully acknowledging the financial support of Graduate Research Fellowship (GRF) and Putra Grant (project code: GP-IPS/2018/9625400) from Universiti Putra Malaysia.

\section{REFERENCES}

Ahmad, J. \& Fatima, N. 2016. Analytical exact solution of neural functional differential equations. Universal Journal of Computational Mathematics 4(2): 24-28.

Baker, C.T., Bocharov, G. \& Rihan, F.A.R. 2008. Neutral delay differential equations in the modeling of cell growth. Applied
Mathematics Group Research Report 2008: 1. Chester, United Kingdom: University of Chester.

Bellen, A. \& Guglielmi, N. 2009. Solving neutral delay differential equations with state dependent delays. Journal of Computational and Applied Mathematics 229(2): 350-362.

Bellen, A., Jackiewicz, Z. \& Zennaro, M. 1988. Stability analysis of one-step methods for neutral delay differential equations. Numerische Mathematik 52(6): 605-619.

Biazar, J. \& Ghanbari, B. 2012. The homotopy perturbation method for solving neutral functional differential equations with proportional delays. Journal of King Saud UniversityScience 24(1): 33-37.

Chen, X. \& Wang, L. 2010. The variational iteration method for solving a neutral functional differential equation with proportional delays. Computers and Mathematics with Applications 59(8): 2696-2702.

Ibrahim, Z.B., Zainuddin, N., Othman, K.I., Suleiman, M. \& Zawawi, I.S.M. 2019. Variable order block method for solving second order ordinary differential equations. Sains Malaysiana 48(8): 1761-1769.

Ishak, F. \& Ramli, M.S.B. 2015. Implicit block method for solving neutral delay differential equations. In AIP Conference Proceedings. Volume 1682: 020054. AIP Publishing.

Ishak, F., Suleiman, M.B. \& Majid, Z.A. 2014. Numerical solution and stability of block method for solving functional differential equations. In Transactions on Engineering Technologies Dordrecht: Springer. pp. 597-609.

Ishak, F., Suleiman, M.B. \& Majid, Z.A. 2013. Block method for solving pantograph type functional differential equations. In Proceedings of the World Congress on Engineering Volume II. 
Ismail, N.I.N., Majid, Z.A. \& Senu, N. 2019. Explicit multistep block method for solving neutral delay differential equation. ASM Science Journal (IQRAC2018) 12(1): 24-32.

Ismail, F., Ahmad, S.Z., Jikantoro, Y.D. \& Senu, N. 2018. Block hybrid method with trigonometric-fitting for solving oscillatory problems. Sains Malaysiana 47(9): 2223-2230.

Jackiewicz, Z. 1987. Variable-step variable-order algorithm for the numerical solution of neutral functional differential equations. Applied Numerical Mathematics 3(4): 317-329.

Jackiewicz, Z. 1986. Quasilinear multistep methods and variable step predictor-corrector methods for neutral functional differential equations. SIAM Journal on Numerical Analysis 23(2): 423-452.

Jackiewicz, Z. 1984. One-step methods of any order for neutral functional differential equations. SIAM Journal on Numerical Analysis 21(3): 486-511.

Jackiewicz, Z. 1982. Adams methods for neutral functional differential equations. Numerische Mathematik 39(2): 221230.

Jackiewicz, Z. \& Lo, E. 2006. Numerical solution of neutral functional differential equations by Adams methods in divided difference form. Journal of Computational and Applied Mathematics 189(1-2): 592-605.

Jackiewicz, Z. \& Lo, E. 1991. The numerical solution of neutral functional differential equations by Adams predictorcorrector methods. Applied Numerical Mathematics 8(6): 477-491.

Kuang, Y. 1993. Delay Differential Equations: With Applications in Population Dynamics. Volume 191. Boston: Academic Press.

Lambert, J.D. 1973. Computational Methods in Ordinary Differential Equations. London: Wiley.

Liu, M., Dassios, I. \& Milano, F. 2019. On the stability analysis of systems of neutral delay differential equations. Circuits, Systems, and Signal Processing 38(4): 1639-1653.

Lv, X. \& Gao, Y. 2013. The RKHSM for solving neutral functional differential equations with proportional delays. Mathematical Methods in the Applied Sciences 36(6): 642-649.

Majid, Z.A. \& Mohamed, N.A. 2019. Fifth order multistep block method for solving volterra integro-differential equations of second kind. Sains Malaysiana 48(3): 677-684.
Majid, Z.A. \& Suleiman, M. 2011. Predictor-corrector block iteration method for solving ordinary differential equations. Sains Malaysiana 40(6): 659-664.

Sakar, M.G. 2017. Numerical solution of neutral functional differential equations with proportional delays. $A n$ International Journal of Optimization and Control: Theories \& Applications (IJOCTA) 7(2): 186-194.

Seong, H.Y. \& Majid, Z.A. 2015. Solving neutral delay differential equations of pantograph type by using multistep block method. In 2015 International Conference on Research and Education in Mathematics (ICREM7). pp. 56-60.

Süli, E. \& Mayers, D.F. 2003. An Introduction to Numerical Analysis. New York: Cambridge University Press.

Wang, W.S. \& Li, S.F. 2007. On the one-leg $\theta$-methods for solving nonlinear neutral functional differential equations. Applied Mathematics and Computation 193(1): 285-301.

Wang, W., Zhang, Y. \& Li, S. 2009. Stability of continuous RungeKutta-Type methods for nonlinear neutral delay differential equations. Applied Mathematical Modelling 33(8): 33193329.

Nur Inshirah Naqiah Ismail \& Norazak Senu Institute for Mathematical Research

Universiti Putra Malaysia

43400 UPM Serdang, Selangor Darul Ehsan

Malaysia

Zanariah Abdul Majid*

Department of Mathematics

Faculty of Science

Universiti Putra Malaysia

43400 UPM Serdang, Selangor Darul Ehsan

Malaysia

*Corresponding author; email: am_zana@upm.edu.my

Received: 26 September 2019

Accepted: 13 January 2020 